CLINICAL STUDY

\title{
Adrenocortical carcinoma and pregnancy: clinical and biological features and prognosis
}

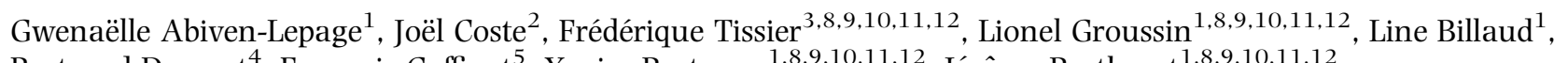
Bertrand Dousset $^{4}$, François Goffinet ${ }^{5}$, Xavier Bertagna ${ }^{1,8,9,10,11,12}$, Jérôme Bertherat ${ }^{1,8,9,10,11,12}$ and Marie-Laure Raffin-Sanson ${ }^{6,7,8,9,10,11,12}$

Departments of ${ }^{1}$ Endocrinology, ${ }^{2}$ Biostatistics, ${ }^{3}$ Pathology, ${ }^{4}$ Surgery and ${ }^{5}$ Obstetrics and Gynecology, Hôpital Cochin, Assistance Publique-Hôpitaux de Paris, Paris, France, ${ }^{6}$ Department of Endocrinology, Hôpital Ambroise Paré, Assistance Publique-Hôpitaux de Paris, 9 Avenue Charles de Gaulle, Boulogne 92100, France, ${ }^{7}$ Faculté de Médecine Paris-Ile de France Ouest, Université de Versailles SQY, Versailles, France, ${ }^{8}$ INSERM U1016, Paris, France, ${ }^{9}$ Institut Cochin, Paris, France, ${ }^{10}$ CNRS UMR8104, Paris, France, ${ }^{11}$ Faculté de Médecine René Descartes, Université Paris 5, Paris F-75014, France and

${ }^{12}$ COMETE Network, Paris, France

(Correspondence should be addressed to M-L Raffin-Sanson at Department of Endocrinology, Hôpital Ambroise Paré, Assistance Publique-Hôpitaux de Paris; Email: marie-laure.raffin-sanson@apraphp.fr)

\begin{abstract}
Objective: Adrenocortical carcinoma (ACC) is a rare, severe disease. Pregnancy-associated ACC has rarely been reported. We wished to evaluate the characteristics and prognosis of ACC diagnosed in patients during pregnancy or in the postpartum period, comparing them with those for ACC diagnosed in nonpregnant women.

Design: Clinical presentation, hormonal secretion, staging, survival, and obstetric data are reported. Patients were included between 1963 and 2007. Mean follow-up was 48 months.

Patients and methods: This is a retrospective cohort study carried out at a referral center. All female patients aged 16-49 years diagnosed with ACC during the observation period were included $(n=110)$. Twelve of these women were pregnant or in the first 6 months after delivery. Hormonal secretion, staging, obstetric data, and survival were analyzed. For the survival analysis, pregnant patients were compared with a subgroup of nonpregnant women matched for age, stage, and year of diagnosis (1 pregnant patient/2 controls).

Results: Adrenocortical tumors diagnosed during pregnancy or in the postpartum period tend to be more often cortisol-secreting tumors $(P=0.06)$ and to be discovered at a more advanced stage than those in nonpregnant women, although the differences were not significant. Fetal outcome was poor. Overall survival of the mother was worse than that of matched controls (hazard ratio of death: 3.98, confidence interval $=1.34-11.85, P=0.013)$.

Conclusion: ACC diagnosed during pregnancy or in the postpartum period is associated with a poor fetal outcome and a poorer prognosis than ACC diagnosed in nonpregnant women.
\end{abstract}

European Journal of Endocrinology 163 793-800

\section{Introduction}

Adrenocortical carcinoma (ACC) is a rare tumor, with an estimated incidence between one and two cases per million adults (1). These tumors have an extremely poor prognosis, with a survival rate of $<30 \%$ at 5 years $(2,3)$. However, the prognosis varies considerably between ACC patients, with some surviving for long periods $(2,4,5)$.

The identification of reliable prognostic factors for predicting the currently unexplained large differences in survival observed in clinical practice is essential for the development of more sensitive means of diagnosis and choice of the most appropriate treatment, particularly after apparently curative surgery, when adjuvant mitotane therapy may be proposed (6). Improvements in our understanding of the physiopathology of ACCs are also required because the treatments currently available are clearly unsatisfactory.

Several clinical data have indicated that there is a relationship between adrenocortical tumors and being female. Adrenocortical tumors are more frequent in women, with a sex ratio of 4.2 (2). Benign and malignant adrenocortical tumors are responsible for $70 \%$ of all cases of Cushing's syndrome (CS) diagnosed during pregnancy $(7,8)$, whereas adrenal tumors account for only $25 \%$ of CS cases diagnosed in nonpregnant female patients. A few cases of pregnancy-dependent ACTH-independent CS have been reported (9-12). However, it remains unknown whether the characteristics of ACC diagnosed during pregnancy, in terms of presentation, secretion or 
progression, are specific to this condition. The detection of ACC during pregnancy remains extremely rare, due to the overall rarity of ACC and the lower fertility of women with hypercortisolism and/or hyperandrogenism: $<20$ cases have been described to date, most reported as isolated cases. Previous studies have shown that hypercortisolism is itself associated with frequent maternal morbidity, and that this condition is associated with a severe fetal prognosis (13). However, it is unknown whether tumor progression is different in cases in which ACC initially develops in a pregnant woman.

In this study, we analyzed clinical and hormonal data at diagnosis and outcome for 12 women with ACC diagnosed during the course of a pregnancy or in the immediate postpartum period. These patients were compared with reproductive age female patients with ACC not being diagnosed during pregnancy, treated over the same period, at a single clinical center.

\section{Patients and methods}

\section{Patients}

In total, 110 reproductive age women (16-49 years) diagnosed with ACC were referred to the Endocrinology Department of Cochin Hospital between 1963 and 2007. The tumor was diagnosed during pregnancy or in the postpartum period in 12 of these cases (11\%). The diagnosis was considered to have been performed during pregnancy if the tumor was diagnosed at any time from the month of the last menstrual period and the delivery date. The postpartum period was defined as the 6 month period beginning from the delivery date. Partial data for eight of these patients have been reported elsewhere $(2,7)$. Nonpregnant women were defined as patients who were not pregnant at the time of diagnosis and who had not been pregnant in the last 6 months (reference group). These patients belonged to a large cohort, reported elsewhere, with additional cases diagnosed during the 2003-2007 period (14).

For each patient, diagnosis was confirmed by pathological examination of the adrenal tumor and/or malignant history and endocrine investigations, as reported previously $(2,14-16)$. All patients were investigated in our department at the time of initial diagnosis, before adrenal surgery, and/or when at the time of tumor recurrence. Assays were performed as described previously $(2,15)$. The values obtained for women diagnosed during pregnancy were compared with those for normal pregnant women at the same stage of gestation.

Tumor stage was determined with the European Network for the Study of Adrenal Tumors staging system (17). Metastases were diagnosed by imaging principally abdominal and chest computed tomography scans - ultrasound scans and magnetic resonance imaging (MRI) were used for pregnant women, and the results obtained were confirmed by pathological examination in cases in which surgery was considered appropriate. The mean duration of follow-up was 48 months (range: 1.2-311).

The study was approved by and carried out in accordance with the recommendations of the ethics committee of Cochin Hospital.

\section{Statistical analysis}

Data are reported as median \pm interquartile range or percentages, as appropriate. Wilcoxon tests and exact $\chi^{2}$ tests were first used to compare the pregnant patients $(n=12)$ and nonpregnant patients $(n=98)$ in terms of clinical presentation, hormonal secretion, and stage of the tumor at discovery. Owing to differences in age, year of diagnosis, secretion status, and stage between pregnant and nonpregnant patients, overall survival and disease-free survival were studied in a second step, using a subsample of 24 nonpregnant patients individually matched with pregnant women for age ( \pm 5 years), secretion status, year of diagnosis, and stage (2:1 matching ratio, i.e. two nonpregnant 'controls' were matched with each pregnant woman). Survival curves were constructed by the Kaplan-Meier method and were compared with Cox's proportional hazards regression models to assess the significance of differences, with adjustment for the matching criteria and tumor size.

\section{Results}

\section{Age distribution and presentation at diagnosis of pregnant/postpartum patients}

Individual clinical and hormonal data are given in Table 1 . The mean age at diagnosis in the pregnant and postpartum women was $28.8 \pm 5.6$ years (mean \pm s.D.), slightly lower than that for the nonpregnant patients (34.1 \pm 10.2$)(P=0.05$; Table 1$)$.

One patient (patient 12), aged 37 at the time of diagnosis, had been diagnosed with MEN1 7 years earlier. Three patients were diagnosed during pregnancy (in the second or third trimester), and nine were diagnosed in the postpartum period. However, the signs and symptoms of hypercortisolism were retrospectively identified as having been present during pregnancy.

The disease was revealed by endocrine features in 9 of the $12(75 \%)$ patients (hypertension, diabetes, morphological changes, muscle wasting, virilization, and depression) and by local or regional manifestations in two patients. One patient had symptomatic hypoglycemia, possibly related to pro-insulin-like growth factor 2 (IGF2) hypersecretion, although the exact mechanism could not be established.

The presentation of pregnancy-associated ACC was similar to that at the time of diagnosis of the 
Table 1 Individual clinical and hormonal data for 12 patients with ACC diagnosed during pregnancy or in the postpartum period.

\begin{tabular}{|c|c|c|c|c|c|c|c|}
\hline Patient & Age & $\begin{array}{l}\text { Time of } \\
\text { diagnosis }\end{array}$ & Clinical signs & $\begin{array}{l}\text { Stage } \\
\text { (ENSAT) }\end{array}$ & $\begin{array}{l}\text { Tumor } \\
\text { weight }(\mathrm{g})\end{array}$ & $\begin{array}{l}\text { Size } \\
(\mathrm{cm})\end{array}$ & Hormone secretion \\
\hline 1 & 32 & $26 \mathrm{GW}$ & Abdominal pain & 2 & 130 & 10 & Cortisol, androgen \\
\hline 2 & 35 & Postpartum & $\begin{array}{l}\text { Muscle wasting, purple striae, } \\
\text { depression }\end{array}$ & 3 & 320 & 7 & Cortisol \\
\hline 3 & 32 & Postpartum & Abdominal pain, fatigue & 2 & NA & 13 & Cortisol \\
\hline 4 & 24 & Postpartum & $\begin{array}{l}\text { Hirsutism, edema, purple striae, } \\
\text { depression }\end{array}$ & 2 & NA & 6.5 & Cortisol, androgen \\
\hline 5 & 32 & $33 \mathrm{GW}$ & Edema, weight gain & 3 & 340 & 11 & Cortisol \\
\hline 6 & 27 & $25 \mathrm{GW}$ & Edema, weight gain, acne & 3 & 1900 & 18 & Cortisol, androgen \\
\hline 7 & 19 & Postpartum & Hypoglycemia & 4 & NS & 13.5 & Cortisol, androgen \\
\hline 8 & 32 & Postpartum & Hirsutism, amenorrhea & 4 & 920 & 15 & Cortisol, androgen \\
\hline 9 & 25 & Postpartum & $\begin{array}{l}\text { No resumption of menses, } \\
\text { hypertension, weight gain }\end{array}$ & 3 & 600 & 10 & Cortisol, androgen \\
\hline 10 & 25 & Postpartum & Weight gain, depression & 3 & 280 & NA & Cortisol, androgen \\
\hline 11 & 24 & Post abortion & High blood pressure & 4 & 714 & 8 & Cortisol, androgen \\
\hline 12 & 37 & Postpartum & Hirsutism & 2 & 446 & 9 & Cortisol, androgen \\
\hline
\end{tabular}

GW, gestational week; NS, no surgery; NA, not available.

nonpregnant patients, in whom the tumor was revealed in 63 of the 98 (64\%) patients by endocrine features and in 19 of the $98(19 \%)$ patients by local extension. However, in 14 of the 98 (14\%) nonpregnant patients, the tumor was revealed as an incidentally discovered mass. This situation did not arise among the pregnant/ postpartum patients.

\section{Hormonal data}

Hormonal investigations showed that the tumors of all 12 patients diagnosed during pregnancy or in the postpartum period secreted cortisol (100\%), either alone $(n=3)$ or together with androgen $(n=9)$ (Table 1$)$. We found that $86(88 \%)$ of the 98 nonpregnant female patients with ACC had a secreting tumor. Seventy-three (74\%) of these patients had cortisol-secreting tumors, $67(68 \%)$ had androgen-secreting tumors, and 12 (13\%) had aldosterone-secreting tumors. Fifty-seven nonpregnant patients had tumors secreting both cortisol and androgen (66\% of secreting tumors), associated in 12 cases with aldosterone, whereas 16 controls had tumors displaying isolated cortisol secretion $(18 \%)$, and 10 had tumors displaying isolated androgen secretion (11\%). Three of the eighty-six nonpregnant patients with cortisol-secreting tumors had tumors that secreted only precursors (Table 2).

These findings suggest that pregnant women are more likely to be diagnosed with a cortisol-secreting tumor than nonpregnant women $(P=0.06)$, although this difference is not statistically significant (see Table 2).

\section{Tumor size and stage at diagnosis}

The tumors of pregnant/postpartum patients tended to be heavier $(627.8 \pm 535.2 \mathrm{~g}$, mean \pm s.D. $)$ than those of nonpregnant patients $(518.73 \pm 595.6)$. However, this difference was not significant $(P=0.09$; Tables 1 and 2$)$.
Four (33\%) pregnant patients had stage 2 tumors, five (43\%) had stage 3 tumors, and three $(25 \%)$ had stage 4 tumors. Thus, two-thirds of these patients displayed local or metastatic extension. In almost two-thirds of the nonpregnant patients, the tumor was limited to the adrenal gland at the time of diagnosis (11/98 (11.22\%) with stage 1 tumors and 49/98 (50\%) with stage 2 tumors), whereas 39 of the 98 (39\%) patients displayed local or metastatic extension: 14 of the $98(14.28 \%)$ patients had stage 3 tumors and 24 of the 98 (24.49\%) patients had stage 4 tumors (NS, $P=0.28$ ).

\section{Treatment}

Only one patient (patient 7) was unable to undergo surgery. This patient had severe local and metastatic extension at the time of diagnosis, with severe hypoglycemia and was in very poor general health. She was treated by hepatic embolization followed by a combination of mitotane and diazoxide. It was not possible to stabilize her condition, and she died 2 months after diagnosis. The other 11 patients diagnosed during pregnancy or in the postpartum period underwent surgical treatment. For the eight patients diagnosed in the postpartum period, surgery was performed within 1 month of diagnosis in most cases. Tumor resection was considered complete in five patients. Patients 11 and 8 displayed complete resection of the adrenal tumor and of metastatic tumors in the liver, but also suffered from pulmonary metastasis. Patient 9 had a locally invasive tumor, and resection was considered unsatisfactory.

Three patients were diagnosed during pregnancy. In patient 1 , an apparently complete ablation of the left adrenal tumor was performed, with a posterolateral extraperitoneal approach, at 29 weeks of gestation. Premature delivery occurred 2 weeks later, after spontaneous membrane rupture. In patient 5 , preterm 
Table 2 Comparison between pregnant/postpartum patients with ACC and nonpregnant patients aged between 16 and 49 years. The characteristics of the 24 matched controls allowing the survival analysis are also shown.

\begin{tabular}{|c|c|c|c|c|c|}
\hline & $\begin{array}{l}12 \text { pregnant/ } \\
\text { postpartum } \\
\text { patients with } \\
\text { ACC }(A)\end{array}$ & $\begin{array}{l}24 \text { matched } \\
\text { controls with } \\
\text { ACC }(B)\end{array}$ & $\begin{array}{l}98 \text { nonpregnant } \\
\text { women with } A C C \\
\text { aged } 16 \text { to } 49(C)\end{array}$ & $\begin{array}{l}\boldsymbol{P}(\mathrm{A}) \\
\text { versus }(\mathrm{B})\end{array}$ & $\begin{array}{l}\boldsymbol{P}(\mathrm{A}) \\
\text { versus }(\mathrm{C})\end{array}$ \\
\hline Age (years) (median \pm IQR) & $29.5 \pm 8.3$ & $30.7 \pm 12.2$ & $36.9 \pm 19.3$ & 0.41 & 0.05 \\
\hline Tumor size $(\mathrm{cm})($ median $\pm I Q R)$ & $10.0 \pm 7.0$ & $9.0 \pm 4.0$ & $10.0 \pm 6.0$ & 0.36 & 0.29 \\
\hline Weight $(\mathrm{g})$ (median $\pm \mathrm{IQR})$ & $275 \pm 431$ & $280 \pm 322$ & $446 \pm 394$ & 0.12 & 0.09 \\
\hline Diagnosis period & & & & $1.00^{*}$ & $0.83^{*}$ \\
\hline Diagnosis < $1980(\%)$ & $2(17)$ & $4(17)$ & $22(20)$ & & \\
\hline Diagnosis $1980-1995(\%)$ & $7(58)$ & $14(58)$ & $58(53)$ & & \\
\hline Diagnosis $>1995(\%)$ & $3(25)$ & $6(25)$ & $18(16)$ & & \\
\hline Hormone secretion (\%) & $12(100)$ & $22(91)$ & $86(87)$ & 0.54 & 0.23 \\
\hline Cortisol & $12(100)$ & $20(83)$ & $73(74)$ & 0.27 & 0.06 \\
\hline Androgen & $7(58)$ & $16(67)$ & 67 (68) & 0.71 & 0.52 \\
\hline Aldosterone & $0(0)$ & $2(8)$ & $12(12)$ & 0.54 & 0.35 \\
\hline Tumor stage & & & & $1.00^{\dagger}$ & $0.28^{\dagger}$ \\
\hline Stage $1(\%)$ & $0(0)$ & $0(0)$ & $11(11)$ & & \\
\hline Stage $2(\%)$ & $4(33)$ & $8(33)$ & $49(50)$ & & \\
\hline Stage 3 (\%) & $5(42)$ & $10(42)$ & $14(14)$ & & \\
\hline Stage 4 (\%) & $3(25)$ & $6(25)$ & $24(25)$ & & \\
\hline
\end{tabular}

IQR, interquartile range.

*Value compares data from all diagnosis periods.

${ }^{\dagger}$ Value compares data from all stages.

labor occurred spontaneously a few days after diagnosis. The infant was stillborn, and surgical treatment was carried out early in the postpartum period. In the remaining patient diagnosed during pregnancy (patient 6), the tumor was apparently completely removed at the time of a preterm cesarean section. Surgery was uncomplicated in these three women, except for the constitution of an abdominal lymphedema in patient 6 .

Ten of the eleven patients treated by surgery also received mitotane treatment. Treatment began 2 or 3 weeks before surgery in three patients, and within 3 months after surgery in four patients. Two patients received mitotane at the time of a recurrence after apparently curative initial surgery (patients 1 and 3). One patient displayed very poor digestive tolerance to mitotane and decided to refuse this treatment after 1 month. The final patient, with a stage 2 extension
(Weiss 6) and no relapse to date (3 years after surgery), has never received mitotane (patient 12). In this patient with MEN1, breast cancer was diagnosed 1 year ago and treated by mastectomy, cytotoxic chemotherapy, and tamoxifen. No relapse of this breast cancer has been observed to date.

Before 2004, the objective was to administer the maximal tolerable dose of mitotane, starting from $6 \mathrm{~g}$ up to $12 \mathrm{~g}$ /day of mitotane (Roussel UCLAF and Pharmacie Centrale des Hôpitaux, Paris, France). After 2004, patients were initially administered $3 \mathrm{~g}$ of Lysodren (mitotane; Bristol-Myers Squibb), this dose subsequently being adapted to give a plasma concentration of $14 \mathrm{mg} / \mathrm{l}$. Patient 3 also received cytotoxic chemotherapy to combat tumor progression on mitotane treatment.

Surgical treatment was carried out on $91(93 \%)$ of the nonpregnant patients. Sixty-nine $(70 \%)$ patients

Table 3 Pregnancy outcome in 12 patients with adrenocortical carcinoma.

\begin{tabular}{lll}
\hline Patient & Fetal complications & Maternal complications \\
\hline 1 & Premature birth (31 GW), intrauterine & Hypertension, diabetes \\
& growth retardation (BW: $1680 \mathrm{~g})$, hypoglycemia & \\
2 & Intrauterine growth retardation (BW: $2047 \mathrm{~g})$ & Diabetes \\
3 & None & Postpartum hemorrhage \\
4 & Premature birth (35 GW, BW: $2900 \mathrm{~g})$ & None \\
5 & Intrauterine fetal death (33 GW) & None \\
6 & Premature birth, intrauterine growth retardation & Hypertension \\
& (27 GW, BW: $1500 \mathrm{~g})$ & None \\
7 & Premature birth (30 GW, BW: $2500 \mathrm{~g})$ & None \\
8 & None & None \\
9 & None & Hypertension, diabetes \\
10 & Premature birth (34 GW) & HELLP syndrome/preeclampsia \\
11 & Second trimester abortion for medical & \\
& reasons (21 GW) & None \\
\hline
\end{tabular}

GW, gestational week; BW, birth weight. 

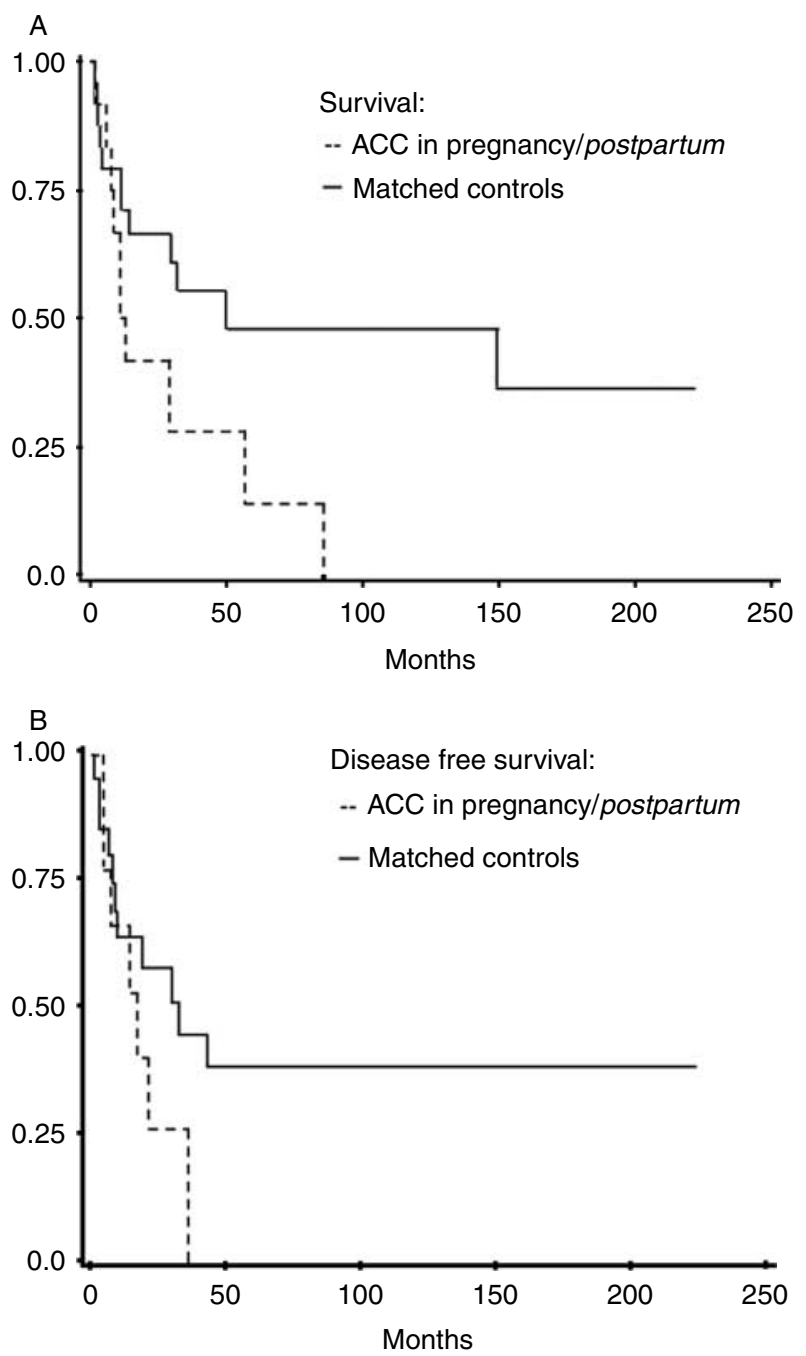

Figure 1 ( $A$ and $B$ ) Survival curves were constructed by the Kaplan-Meier method and were compared, with the significance of differences between curves being assessed with Cox's proportional hazards regression models. Survival $(A)$ and diseasefree survival (B) curves are shown in dashed lines $(---)$ for pregnant or postpartum patients and in black lines (-) for matched nonpregnant patients. Pregnancy was associated with a shorter survival $(P=0.013)$ and a shorter disease-free survival in pregnant patients, although this last difference was not statistically significant $(P=0.20)$.

received mitotane treatment, initiated either within 3 months after removal of the primary tumor or at a later time point. Cytotoxic chemotherapy, based on various drug regimens, was administered to 13 patients.

Thus, the choice of treatment was similar in the pregnant/postpartum patients and in nonpregnant patients.

\section{Pregnancy outcome}

Pregnancy was uncomplicated in only four of the cases of ACC diagnosed during pregnancy or in the postpartum period (Table 3). Maternal morbidity was observed in five cases: three patients had hypertension and three developed diabetes mellitus (one patient developing both conditions). ACC was diagnosed in one patient shortly after a second trimester abortion for medical reasons, due to life-threatening hypertension and severe thrombopenia leading to HELLP syndrome with preeclampsia.

Fetal cases of morbidity and mortality included two deaths (one abortion for medical reasons and one stillbirth). The frequency of preterm birth was high: five children were born before 37 weeks, including three born before 32 weeks. One of these children suffered from severe membrane hyaline disease. Three patients gave birth to hypotrophic infants (birth weight $\leq 2$ s.D. on Lubchenko's curve). Four female infants born to mothers with androgen-secreting ACC had no genital ambiguity.

\section{Survival}

None of the women died during the course of their pregnancy. However, the survival rate of pregnant women was only $50 \%$ at 1 year, $28 \%$ at 3 years, $13 \%$ at 5 years, and $0 \%$ at 8 years. Diagnosis during pregnancy or in the postpartum period was associated with a shorter survival than for 'controls' (Fig. 1A; hazard ratio $(\mathrm{HR})=3.98$, 95\% confidence interval $=$ $1.34-11.85, P=0.013$, adjusted for tumor size) and a shorter disease-free survival, although this second difference was not significant (Fig. $1 \mathrm{~B}$; $\mathrm{HR}=1.92,95 \%$ confidence interval $=0.71-5.17, P=0.20$ ). If the analysis was restricted to the subgroup of women with cortisol-secreting tumors (all pregnant and $88 \%$ of nonpregnant patients), the association with survival was only slightly weaker $(\mathrm{HR}=2.42,95 \%$ confidence interval $=0.88-6.69$, adjusted for tumor size), excluding the possibility of a confounding effect of cortisol secretion.

\section{Discussion}

ACC during pregnancy is rare. Only 12 of 140 cases of $\mathrm{CS}$ revealed during pregnancy and published before 2005 were found to be due to an ACC, these cases being reported mostly as small series or isolated cases $(13,18)$. We report here the characteristics of 12 patients diagnosed with ACC during pregnancy or in postpartum period, and a comparison of these patients with a cohort of 98 nonpregnant women under the age of 50 years treated at the same center.

Pregnancy-associated ACC tended to be discovered at a more advanced stage and with larger tumors than that observed in the group of nonpregnant patients. We cannot exclude the possibility of more rapid tumor progression during pregnancy, but diagnostic difficulties probably account for this more severe presentation (19). This is probably why 9 of the 12 patients concerned were diagnosed during the postpartum period, although it was clear, retrospectively, that hypercortisolism was present during pregnancy. 
As in all cases of CS-associated pregnancy, fetal prognosis was poor. Premature births, intrauterine growth retardation, stillbirths, and intrauterine deaths have been reported in all studies (13, 20-22). The prognosis may be improved by treating the cause of hypercortisolism during pregnancy (13). Unfortunately, in most of the cases reported here, diagnosis was made after delivery. One of the fetal losses (abortion for medical reasons in patient 11) occurred before diagnosis, and the other, very shortly after diagnosis, before any decision about treatment could be taken (patient 5). A greater awareness of this rare disorder might increase the frequency of early diagnosis, making it possible to initiate treatment early, possibly improving the outcome for both mother and fetus.

The overall prevalence of secreting tumors was higher in both pregnant and nonpregnant groups than that in previously reported studies on ACC. This discrepancy may be due to differences in the extent of hormonal investigations, or the higher frequency of functional tumors in women than in men $(2,23,24)$. The frequency of cortisol-secreting tumors in cases of pregnancy-associated ACC was even higher than that in the nonpregnant women. Given the antigonadotrophic effect of cortisol and the high frequency of miscarriage in women with CS, we would have expected an excess of nonsecreting tumors among pregnant women. Occasional cases of recurrent ACTH-independent cortisol secretion during pregnancy, with spontaneous remission after delivery, have been reported $(10,11,25)$. However, in the cases described here, cortisol secretion persisted after delivery.

The prognosis of ACC is extremely poor, but pregnancy-associated ACC is associated with even shorter survival periods than that observed in matched nonpregnant controls. Tumor stage at initial diagnosis is the most clear-cut and best validated prognostic factor for overall survival $(3,14,17,23)$. Older age has also frequently been identified as a prognostic factor (14). Some other potential prognostic factors have also been identified, but not consistently in all studies $(14,26,27)$. Thus, controls were carefully matched on the basis of these two factors and were selected from women diagnosed during the same period of time, at the same center, to ensure that the two groups had been treated similarly. The diagnosis of a new cancer during pregnancy does not, in general, result in a higher risk of cause-specific death than the diagnosis of the same cancer in nonpregnant or nonlactating women $(28,29)$. Breast cancer is the most notable exception, as lactating women with breast cancer have been shown to have a worse outcome $(29,30)$, even if adjustment is made for age and extent of disease (31). However this observation has not been confirmed in all studies (32). There may be several reasons for the shorter survival in patients with pregnancy-associated ACC. No maternal death directly due to hypercortisolism was observed. Late treatment due to the pregnancy is also unlikely because all women underwent surgical and/or medical treatment, as usually indicated, very soon after the diagnosis was established. It has been suggested that cortisol hypersecretion is associated with a worse prognosis (14). This may contribute to the severe prognosis of the tumors occurring in pregnant women. However, it is unlikely to account for the difference in survival between pregnant women with ACC and controls, as pregnant women had a worse prognosis even after the exclusion of tumors that did not secrete cortisol. So, is tumor progression influenced by pregnancy. There have been several reports of recurrent ACTH-independent CS occurring during pregnancy and displaying spontaneous remission after delivery $(10,11,25)$. However, these cases concerned benign ACTH-independent hypercortisolism, with pregnancy affecting only cortisol secretion, but not tumor proliferation.

Some of the molecular characteristics of adrenal tumors are reminiscent of the physiology of the fetal adrenal cortex: very high levels of IGF2 (as compared with those in normal adult adrenal gland) are present in ACC as in the fetal zone of adrenal glands $(15,33)$. Similarly, the CREB was barely detectable in ACC and in the fetal zone of the adrenal gland, whereas it is clearly detectable in adult adrenal gland (34). Sensitivity to human chorionic gonadotrophin has clearly been demonstrated in cases of ACTH-independent macronodular adrencortical hyperplasia (35), but the effect of pregnancy-associated factors on ACC proliferation, as observed in the fetal zone of the adrenal cortex, remains hypothetical.

We recently demonstrated expression of the progesterone receptor (PR or PGR) and estrogen receptor $\beta$ (ER $\beta$ or ESR2) in normal adrenal gland, adrenal tumors, and the H295R adrenocortical cell line. The levels of expression of these receptors on these cells are of the same order of magnitude or higher than those observed in normal breast and breast carcinoma (36). Montanaro et al. (37) previously demonstrated that 4 $(\mathrm{OH})$ tamoxifen and ICI 182 780, a SERM and pure antiestrogen, respectively, upregulated ER $\beta$ levels and inhibited cell proliferation in the H295R human adrenal cell line. Their role in vivo remains unclear, but the presence of these receptors on adrenal and breast tumors, the prognosis of which seems to be modified by pregnancy, is striking.

The more aggressive course of ACC is not limited to the period of exposure to hormonal changes associated with pregnancy, as most patients were diagnosed or had most of their follow-up in the postpartum period. Could pregnancy favor the development of a particular pattern of tumorigenesis characterized by more frequent cortisol secretion and a more aggressive progression? A recent study demonstrated that gene profiling differentiates between two types of adrenocortical cancers with different prognoses. This suggests that there may be various types of tumor proliferation, associated with different clinical outcomes (38). In particular, 
pregnancy-related breast tumors express significantly lower levels of ER and PR than the equivalent tumors in nonpregnant women, a profile generally associated with a worse prognosis (39). Unfortunately, no data is available concerning the gene expression profiles or the ER or PR status of the tumors diagnosed in the pregnant women reported here.

Considering the rarity of this condition, it is difficult to provide recommendations on how to treat pregnant patients with ACC, adapted to the term and the stage of the tumor. However, from our limited experience, we know that adrenal surgery after MRI evaluation is possible during pregnancy. As complete surgical ablation of the tumor is the most efficient treatment of ACC, we recommend it whatever be the term. Preterm delivery is an obvious risk, especially in the third trimester, and collaboration with the obstetrical team is mandatory. Pulmonary maturation should be discussed. Because of the very poor prognosis of pregnancy-associated tumors, OP'DDD treatment could be offered, even in tumors limited to the adrenal gland. OP'DDD cannot be recommended during pregnancy, even if an uncomplicated pregnancy has been reported under mitotane treatment, but prescribed as soon as possible after delivery. Thus, breastfeeding is not recommended. Abortion for medical reason may be discussed if ACC is discovered during the first trimester, especially in stages 3 and 4 .

In conclusion, we have shown that ACC diagnosed during pregnancy or in the postpartum period is associated with a worse prognosis than ACC diagnosed in nonpregnant women. These findings should lead to a more aggressive treatment in this subgroup of patients, even in cases of apparently complete surgical resection.

\section{Declaration of interest}

The authors declare that there is no conflict of interest that could be perceived as prejudicing the impartiality of the research reported.

\section{Funding}

This work was supported in part by a Plan Hospitalier de Recherche Clinique grant to the COMETE Network (AOM 06-179) and by the Conny-Maeva Foundation.

\section{References}

1 Grumbach MM, Biller BM, Braunstein GD, Campbell KK, Carney JA, Godley PA, Harris EL, Lee JK, Oertel YC, Posner MC, Schlechte JA \& Wieand HS. Management of the clinically unapparent adrenal mass ("incidentaloma”). Annals of Internal Medicine 2003138 424-429.

2 Luton JP, Cerdas S, Billaud L, Thomas G, Guilhaume B, Bertagna X, Laudat MH, Louvel A, Chapuis Y, Blondeau P, Bonnin A \& Bricaire H. Clinical features of adrenocortical carcinoma, prognostic factors, and the effect of mitotane therapy. New England Journal of Medicine $1990 \mathbf{3 2 2}$ 1195-1201. (doi:10.1056/ NEJM199004263221705)
3 Allolio B \& Fassnacht M. Clinical review: adrenocortical carcinoma: clinical update. Journal of Clinical Endocrinology and Metabolism 200691 2027-2037. (doi:10.1210/jc.2005-2639)

4 Harrison LE, Gaudin PB \& Brennan MF. Pathologic features of prognostic significance for adrenocortical carcinoma after curative resection. Archives of Surgery 1999134 181-185. (doi:10.1001/ archsurg.134.2.181)

5 Tritos NA, Cushing GW, Heatley G \& Libertino JA. Clinical features and prognostic factors associated with adrenocortical carcinoma: Lahey Clinic Medical Center experience. American Journal of Surgery 200066 73-79.

6 Terzolo M, Angeli A, Fassnacht M, Daffara F, Tauchmanova L, Conton PA, Rossetto R, Buci L, Sperone P, Grossrubatscher E, Reimondo G, Bollito E, Papotti M, Saeger W, Hahner S, Koschker AC, Arvat E, Ambrosi B, Loli P, Lombardi G, Mannelli M, Bruzzi P, Mantero F, Allolio B, Dogliotti L \& Berruti A. Adjuvant mitotane treatment for adrenocortical carcinoma. New England Journal of Medicine 2007356 2372-2380. (doi:10.1056/NEJMoa063360)

7 Guilhaume B, Sanson ML, Billaud L, Bertagna X, Laudat MH \& Luton JP. Cushing's syndrome and pregnancy: aetiologies and prognosis in twenty-two patients. European Journal of Medicine 19921 83-89.

8 Lindsay JR \& Nieman LK. Adrenal disorders in pregnancy. Endocrinology and Metabolism Clinics of North America 200635 1-20 (v). (doi:10.1016/j.ecl.2005.09.010)

9 Caticha O, Odell WD, Wilson DE, Dowdell LA, Noth RH, Swislocki AL, Lamothe JJ \& Barrow R. Estradiol stimulates cortisol production by adrenal cells in estrogen-dependent primary adrenocortical nodular dysplasia. Journal of Clinical Endocrinology and Metabolism 1993 77 494-497. (doi:10.1210/jc.77.2.494)

10 Close CF, Mann MC, Watts JF \& Taylor KG. ACTH-independent Cushing's syndrome in pregnancy with spontaneous resolution after delivery: control of the hypercortisolism with metyrapone. Clinical Endocrinology 199339 375-379. (doi:10.1111/j.13652265.1993.tb02380.x)

11 Wallace C, Toth EL, Lewanczuk RZ \& Siminoski K. Pregnancyinduced Cushing's syndrome in multiple pregnancies. Journal of Clinical Endocrinology and Metabolism 199681 15-21. (doi:10. $1210 /$ jc. 81.1 .15$)$

12 Kasperlik-Zaluska AA, Szczupacka I, LeszczynskaBystrzanowska J \& Drus-Przybyszewska G. Pregnancy-dependent Cushing's syndrome in three pregnancies. British Journal of Obstetrics and Gynecology $2000 \mathbf{1 0 7} 810-812$.

13 Lindsay JR, Jonklaas J, Oldfield EH \& Nieman LK. Cushing's syndrome during pregnancy: personal experience and review of the literature. Journal of Clinical Endocrinology and Metabolism 200590 3077-3083. (doi:10.1210/jc.2004-2361)

14 Abiven G, Coste J, Groussin L, Anract P, Tissier F, Legmann P, Dousset B, Bertagna X \& Bertherat J. Clinical and biological features in the prognosis of adrenocortical cancer: poor outcome of cortisol-secreting tumors in a series of 202 consecutive patients. Journal of Clinical Endocrinology and Metabolism $2006 \mathbf{9 1}$ 2650-2655. (doi:10.1210/jc.2005-2730)

15 Gicquel C, Bertagna X, Gaston V, Coste J, Louvel A, Baudin E, Bertherat J, Chapuis Y, Duclos JM, Schlumberger M, Plouin PF, Luton JP \& Le Bouc Y. Molecular markers and long-term recurrences in a large cohort of patients with sporadic adrenocortical tumors. Cancer Research 200161 6762-6767.

16 Tissier F, Cavard C, Groussin L, Perlemoine K, Fumey G, Hagnere AM, Rene-Corail F, Jullian E, Gicquel C, Bertagna X, Vacher-Lavenu MC, Perret C \& Bertherat J. Mutations of beta-catenin in adrenocortical tumors: activation of the Wnt signaling pathway is a frequent event in both benign and malignant adrenocortical tumors. Cancer Research 200565 7622-7627.

17 Fassnacht M, Johanssen S, Quinkler M, Bucsky P, Willenberg HS, Beuschlein F, Terzolo M, Mueller HH, Hahner S \& Allolio B. Limited prognostic value of the 2004 International Union Against Cancer staging classification for adrenocortical carcinoma: proposal for a revised TNM Classification. Cancer 2009115 243-250. (doi:10.1002/cncr.24030)

18 Klibanski A, Stephen AE, Greene MF, Blake MA \& Wu CL. Case records of the Massachusetts General Hospital. Case 36-2006. 
A 35-year-old pregnant woman with new hypertension. New England Journal of Medicine 2006355 2237-2245. (doi:10.1056/ NEJMcpc069027)

19 Raffin-Sanson ML, Massias JF, Ankotche A, Coste J, de Keyzer Y, Oliver C, Dumont C, Cabrol D, Ferre F \& Bertagna X. High precursor level in maternal blood results from the alternate mode of proopiomelanocortin processing in human placenta. Clinical Endocrinology 199950 85-94. (doi:10.1046/j.1365-2265.1999. 00612.x)

20 Murakami S, Saitoh M, Kubo T, Kawakami Y \& Yamashita K. A case of mid-trimester intrauterine fetal death with Cushing's syndrome. Journal of Obstetrics and Gynaecology Research 199824 153-156. (doi:10.1111/j.1447-0756.1998.tb00067.x)

21 Cabezon C, Bruno OD, Cohen M, Garcia S \& Gutman RA. Twin pregnancy in a patient with Cushing's disease. Fertility and Sterility 199972 371-372. (doi:10.1016/S0015-0282(99)00261-7)

22 Lo KW \& Lau TK. Cushing's syndrome in pregnancy secondary to adrenal adenoma. A case report and literature review. Gynecologic and Obstetric Investigation $1998 \mathbf{4 5}$ 209-212. (doi:10.1159/ 000009958 )

23 Icard P, Goudet P, Charpenay C, Andreassian B, Carnaille B, Chapuis Y, Cougard P, Henry JF \& Proye C. Adrenocortical carcinomas: surgical trends and results of a 253-patient series from the French Association of Endocrine Surgeons Study Group. World Journal of Surgery 200125 891-897. (doi:10.1007/ s00268-001-0047-y)

24 Venkatesh S, Hickey RC, Sellin RV, Fernandez JF \& Samaan NA. Adrenal cortical carcinoma. Cancer 198964 765-769. (doi:10. 1002/1097-0142(19890801)64:3 < 765::AID-CNCR28206403 $33>3.0 . C O ; 2-\mathrm{I})$

25 Hana V, Dokoupilova M, Marek J \& Plavka R. Recurrent ACTH-independent Cushing's syndrome in multiple pregnancies and its treatment with metyrapone. Clinical Endocrinology 2001 54 277-281. (doi:10.1046/j.1365-2265.2001.01055.x)

26 Stojadinovic A, Ghossein RA, Hoos A, Nissan A, Marshall D, Dudas M, Cordon-Cardo C, Jaques DP \& Brennan MF. Adrenocortical carcinoma: clinical, morphologic, and molecular characterization. Journal of Clinical Oncology 200220 941-950. (doi:10.1200/ JCO.20.4.941)

27 Assie G, Antoni G, Tissier F, Caillou B, Abiven G, Gicquel C, Leboulleux S, Travagli JP, Dromain C, Bertagna X, Bertherat J, Schlumberger M \& Baudin E. Prognostic parameters of metastatic adrenocortical carcinoma. Journal of Clinical Endocrinology and Metabolism 200792 148-154. (doi:10.1210/jc.2006-0706)

28 Jacobs IA, Chang CK \& Salti GI. Coexistence of pregnancy and cancer. American Surgeon 200470 1025-1029.

29 Stensheim H, Moller B, van Dijk T \& Fossa SD. Cause-specific survival for women diagnosed with cancer during pregnancy or lactation: a registry-based cohort study. Journal of Clinical Oncology 200927 45-51. (doi:10.1200/JCO.2008.17.4110)

30 Bladstrom A, Anderson H \& Olsson H. Worse survival in breast cancer among women with recent childbirth: results from a Swedish population-based register study. Clinical Breast Cancer 20034 280-285. (doi:10.3816/CBC.2003.n.033)
31 Guinee VF, Olsson H, Moller T, Hess KR, Taylor SH, Fahey T, Gladikov JV, van den Blink JW, Bonichon F, Dische S, Yates JW \& Cleton FJ. Effect of pregnancy on prognosis for young women with breast cancer. Lancet $1994 \quad 343 \quad 1587-1589$. (doi:10.1016/ S0140-6736(94)93054-6)

32 Beadle BM, Woodward WA, Middleton LP, Tereffe W, Strom EA, Litton JK, Meric-Bernstam F, Theriault RL, Buchholz TA \& Perkins GH. The impact of pregnancy on breast cancer outcomes in women $<$ or =35 years. Cancer $20091151174-1184$. (doi:10.1002/cncr.24165)

33 Mesiano S \& Jaffe RB. Developmental and functional biology of the primate fetal adrenal cortex. Endocrine Reviews $1997 \mathbf{1 8}$ 378-403. (doi:10.1210/er.18.3.378)

34 Rosenberg D, Groussin L, Jullian E, Perlemoine K, Medjane S, Louvel A, Bertagna $X$ \& Bertherat J. Transcription factor $3^{\prime}, 5^{\prime}$-cyclic adenosine $5^{\prime}$-monophosphate-responsive elementbinding protein (CREB) is decreased during human adrenal cortex tumorigenesis and fetal development. Journal of Clinical Endocrinology and Metabolism $2003 \mathbf{8 8}$ 3958-3965. (doi:10. 1210/jc.2003-030070)

35 Lacroix A, Hamet P \& Boutin JM. Leuprolide acetate therapy in luteinizing hormone - dependent Cushing's syndrome. New England Journal of Medicine 1999341 1577-1581. (doi:10. 1056/NEJM199911183412104)

36 de Cremoux P, Rosenberg D, Goussard J, Bremont-Weil C, Tissier F, Tran-Perennou C, Groussin L, Bertagna X, Bertherat J \& Raffin-Sanson ML. Expression of progesterone and estradiol receptors in normal adrenal cortex, adrenocortical tumors, and primary pigmented nodular adrenocortical disease. EndocrineRelated Cancer 200815 465-474. (doi:10.1677/ERC-07-0081)

37 Montanaro D, Maggiolini M, Recchia AG, Sirianni R, Aquila S, Barzon L, Fallo F, Ando S \& Pezzi V. Antiestrogens upregulate estrogen receptor beta expression and inhibit adrenocortical H295R cell proliferation. Journal of Molecular Endocrinology 2005 35 245-256. (doi:10.1677/jme.1.01806)

38 de Reynies A, Assie G, Rickman DS, Tissier F, Groussin L, ReneCorail F, Dousset B, Bertagna X, Clauser E \& Bertherat J. Gene expression profiling reveals a new classification of adrenocortical tumors and identifies molecular predictors of malignancy and survival. Journal of Clinical Oncology 200927 1108-1115. (doi:10.1200/JCO.2008.18.5678)

39 Bonnier P, Romain S, Dilhuydy JM, Bonichon F, Julien JP, Charpin C, Lejeune C, Martin PM \& Piana L. Influence of pregnancy on the outcome of breast cancer: a case-control study. Societe Francaise de Senologie et de Pathologie Mammaire Study Group. International Journal of Cancer $1997 \mathbf{7 2}$ 720-727. (doi:10.1002/(SICI)10970215(19970904)72:5<720::AID-IJC3 > 3.0.CO;2-U)

Received 24 July 2010

Accepted 10 August 2010 